DOI: $10.17805 /$ zpu.2017.2.18

\title{
Социальность учителей: внешние и внутренние условия*
}

\author{
М. Н. КОЖЕВНИКОВА \\ ИНСТИТУТ УПРАВЛЕНИЯ ОБРАЗОВАНИЕМ РОССИЙСКОЙ АКАДЕМИИ ОБРАЗОВАНИЯ, \\ Г. САНКТ-ПЕТЕРБУРГ
}

В статье исследуется проблема социальности педагогов и условий ее становления внешних и внутренних. Социальность понимается автором как способность к общности с Другими (учащимися, коллегами, образовательными институциями), а социальность педагогов - как имеющая особенности в плане границ общности; модуса отношений с Другими и типа включенности в социум.

Вопрос о социальности учителей оказывается важен для прояснения истоков конформности в обществе и конформности в образовании. С чего начинается профессиональная конформность учителей? Автор вычленяет элементы социальности педагогов, в зависимости от которых определяются внутренние и внешние факторы.

Внутренние факторы выражены в профессиональном самосознании и представлены в комплексе пониманий, позиций, переживания личностных смыслов и личностной ответственности в самосознании учителя. Они составляют проблематику личной миссии учителя, определяют саму трактовку профессионального социума со стороны педагогов.

Внешние факторы относятся к уровню включения педагогов в профессиональный социум, бывают выражены в принципах организации педагогического социума. Их определяют институциональные и управленческие модели. Эти факторы выявляются в формировании социальных позиций педагогов, в принимаемой ими институциональной роли и т. д. В связи с этими позициями и ролями обычной для социума педагогов ситуацией оказывается противостояние активной административной «власти центра» и «власти периферии», или пассивного большинства.

Текущая общественная ситуация в России и на Западе определяется растущим влиянием идеологии неолиберализма. В образовании это влияние ведет к росту отчуждения учителей от их собственных ценностных оснований. Социальная идентичность учителей в педагогическом коллективе при этом может формироваться в двух направлениях: «принятой коллективной» (конформистской) или «рефлективной социальной» идентичности. Однако подлинная общность учительского сообщества возникает лишь во втором случае. Из внешних факторов важнейшим условием для этого является синергетический тип управления в образовании, о необходимости которого пишет автор.

Ключевые слова: социальность; личная миссия учителя; профессиональное самосознание педагогов; вмененная ответственность; конформность; скрытый учебный план; социальная идентичность; синергетическая модель управления

\section{ВВЕАЕНИЕ}

$\mathrm{B}$ нашу эпоху, которая, сопоставляя учителя-человека с идеальной педагогической машиной (компьютером, искусными информационными технологиями), ставит вопрос о том, будет ли в образовании вообще нужен живой учитель, становятся особенно важными внутренние профессиональные основания роли «учителя-человека».

* Исследование выполнено при поддержке РФФИ (проект «Проблема становления социальности в образовании», грант № 13-03-00276, а также в рамках финансирования госзадания по теме НИР «Теоретико-методологические основы разработки прогностических моделей развития непрерывного педагогического образования» (проект № 1764).

The research was performed in the framework of the funding by RFBR (project research «The Problem of the Formation of Sociality in Education», grant No. 13-03-00276), and also in the framework of the funding of the state assignment for research theme: «Theoretical and Methodological Basis for the Development of Predictive Models of Development of Continuous Pedagogical Education» (project No. 1764). 
Эти основания - та составляющая «учителя», которая специфично человечна и социальна, т. е. выходит за рамки «носителя знаний» и «технолога обучения». Мы исходим здесь из своей трактовки социальности (Кожевникова, 2016: 44-45) как «способности к общности с Аругими», ведущей к включенности в многообразные отношения с отдельно взятыми Аругими и в плотный мир отношений коллективных Аругих и всех установлений социума.

Социальность педагогов обнаруживает свои особенности в плане границ этой общности (это общность образовательного сообщества); модуса отношений с отдельно взятыми Аругими - профессиональные педагогические отношения с учащимися или коллегами-педагогами и типа включенности в плотный мир отношений и установлений коллективных Аругих - образовательные институции. В связи с трактовкой социальности как способности к общности зачастую появляются такие версии понимания целей и путей формирования общности в образовании, которые в действительности ведут к утверждению конформности как идеала и нормы. Эту проблему нам требуется заметить и прояснить.

Как было сказано, человечная и социальная составляющая «учителя» - предмет нашего обсуждения. Тогда первый вопрос, встающий в связи с этим: состоит ли роль «учителя-человека» в том, чтобы передавать ученикам свой человеческий опыт? Или представлять собой идеал, образец человека? Или, может быть, представить ученикам себя со своей деятельностью, мышлением, чувствованиями, мотивацией, отношениями, ценностями на рассмотрение в качестве модели человека? (И в последнем случае нам требуется отличить идеал от модели).

Наконец, практические вопросы: при каких условиях возможна социальность педагогов как способность к общности с Аругими? То есть о чем следует заботиться образовательной политике и теории, а также практике педагогического образования?

\section{ВНУТРЕННИЕ УСАОВИЯ СОЦИААЬНОСТИ: САМОСОЗНАНИЕ ПЕААГОГА. ПРОБАЕМА АИЧНОЙ МИССИИ УЧИТЕАЯ}

Наш первый ответ: внутренние условия социальности - это живое профессиональное самосознание педагога, соответственно, перед нами встают следующие задачи: выявлять, поддерживать, культивировать самосознание педагога. В связи с этим требуется обсудить проблему личной миссии учителя.

Согласно А. В. Уткину в России в X-XVII вв. учительство рассматривалось как духовная традиция. Вплоть до XVIII в. миссия учителя определялась как отвлеченная философско-педагогическая проблема, как духовная ипостась. Затем до ХХ в. взгляды менялись, миссия учителя последовательно трактовалась как просветительская, образовательная, социально-педагогическая и, наконец, как метакатегория, отражающая культурно-историческую направленность и социально-творческое начало педагогической деятельности (Уткин, 2013: 450-451).

В наше время, в XXI в., миссия педагога понимается во многом в свете пересечения взгляда на ее трактовку в институциональном аспекте с взглядом со стороны социального запроса (Курлов, 2004). Вместе с тем ученые гуманистической педагогики критикуют менеджеристское выхолащивание смыслов самого понятия «миссия» (как это делается в сфере бизнеса) и поднимают вопрос о необходимости возвращения к духовной составляющей понятия, сращенной с идеей служения ( «миссионного подхода»), и к определению миссии в образовании через менталитет, предлагая в итоге «ментально-миссионный подход» (Белкин, Сутырина, 2009). В исследованиях психо- 
логии миссионного подхода в образовании, прекрасный пример которых представляет работа Е. С. Малашкиной (Малашкина, 2006), условием развития культуры отношения учителя к профессиональной деятельности понимается отношение к ней как к миссии. Последнее же трактуется как идеал - и в итоге находит свой фундамент в духовно-религиозном обосновании учительской деятельности как религиозно понимаемого феномена - «доброделания» (Малашкина, 2007). Полагаем, проблема «миссии учителя» связана со всеми этими вопросами и обосновано вызывает особый интерес гуманистической педагогики (Малякова, 2014) и философии образования (включая нашу же собственную работу прошлых лет) (Кожевникова, 2014).

В данной статье согласно нашей концепции личная миссия учителя как философско-образовательный концепт с его основаниями и әлементами трактуется принципиально в связи с профессиональным учительским самосознанием и приобретает особое значение в контексте становления социальности педагогов.

Первый әлемент проблемы, который следует выделить, состоит в том, что в педагогике сложилась широко известная интерпретация, которую можно описать как подразумевающую, по существу, «вмененную миссию». Это объективировано деонтологическая категория того же модуса, что «вмененная ответственность» (Гусейнов, 2001: 202). В чем она выражается? Можно сказать, что это ожидание и даже требование со стороны всего общества, чтобы учитель исполнял как долг заданную ему миссию и целый список целей и задач. Вместе с тем «долг» мы различаем с должным: второе обнаруживается изнутри, а первый распознается как то, что объективировано, задано человеку извне.

Список целей и задач, обязательных к исполнению, претерпевает уточнения с каждой новой эпохой, но всегда эти цели и задачи весьма высоки, тяготея к абсолютизированным. Кроме того, в ожидания и возложенный «долг» входят и те характеристики, которые для учителя оказываются квалификационными. В наше время таковыми оказываются характеристики, предъявляемые современным профессиональным стандартом педагога.

Идеальным случаем был бы тот, когда нашелся бы учитель, который, обладая требуемыми характеристиками, кроме того, самостоятельно поставил бы перед собой все должные цели и задачи. В этом случае осуществилась бы ожидаемая обществом миссия, и она оказалась бы не вмененной, а собственной, добровольной. Однако если посмотреть на звучавшие в истории педагогики в разные времена цели, задачи педагога и ожидаемые от него характеристики, то все они требуют такого совершенства, в котором простые смертные никогда замечены не были. Так что этот идеал в истории образования представляли только святые, случавшиеся среди учителей.

Что же происходит обычно? Один вариант: учитель решительно декларирует наличие у него ожидаемой миссии, закрывая глаза на существующий разрыв своей реальности с идеалом. Он принимает навязанную абсолютизированную миссию за собственную и в итоге (в худшем случае) лицемерит или (в лучшем случае) самообманывается. Свою же личную ответственность он понимает как «долг» (в объясненном выше смысле).

Во втором варианте на фоне того, что «миссия учителя» - недосягаемый идеал, реющий над головой педагога в горних высях, в учительской среде возникает крайняя позиция, противостоящая перфекционизму «вмененной миссии», - позиция «ограниченных функций»: «Я не бог! Все, что я делаю, это от учитель понимает «от - и до» вмененной ответственности (профессиональных обязанностей). Автору в общении с педагогами доводилось слышать это в следующих 
формулировках: «K чему эта лирика: разговоры про собственную заинтересованность учителя и про любовь учителя к детям! Мы профессионалы и выполняем свой долг перед государством. Наше дело - вьучить чтению, счету и прочему, ито прописано ». Современная эпоха рыночных отношений и тотального менеджмента добавила оснований для этой позиции, сводя былые возвышенные идеи миссии к ясно прописанному функционалу.

Герой книги А. Иванова «Географ глобус пропил» Виктор Служкин в своей роли учителя географии разыграл эту крайность преодоления «лирики» заинтересованности и любви, отвечая на реплики учеников «неинтересно»:

- А кому интересно? - удивился Служкин. - Мне, что ли?

- Так увольняйтесь, - с первой парты посоветовал верзила Старков, кандидат в медалисты.

- Кто ж тогда моих малых деток и старушку мать кормить будет? - спросил Служкин...

(Иванов: Электронный ресурс)

И дальше здесь же он демонстрирует ученикам пример полного отказа от «миссии» в мотивации учительской деятельности, шокируя их в особенности предложением абсолютизировать экономические отношения в образовании, при которых редуцируется само образование: «Или давайте так: вы мне платите деньги, а я вас отпускаю с урока». Поскольку Служкин вообще все делает неправильно, производя этим бурление событий против глади хода по течению (образ Служкина в этом-то смысле - peмейк Иванушки-дурачка из русской сказки), то и здесь, случайно или намеренно, он выявляет, как вся деятельность учителя искажается кардинально, как только из нее выпадают не экономические, а человеческие смыслы, принятые в дичную мотивацию деятеля.

Третьим вариантом из возможных будет «дичная миссия учителя», коррелирующая с «личной миссией» человека. (Последнее осуществимо при наличии человекаучителя). В этом случае подразумевается, что учитель определяет сам направление и смысл деятельности, руководствуясь своими природными наклонностями, сложившимися интересами, прошедшими через него линиями ( «нитями») судьбы. Так, Служкин с детства сам относился к рекам, «как к иконам» («всюду в природе разлито чувство, но только в реках содержится мысль»), поэтому взялся приобщить своих хулиганистых учеников к рекам и передать им «вечное влечение дорог». Исходя из своего языкового дарования, он стал читать малокультурным подросткам стихи, юмористические и лирические, вместо сухих замечаний в проверяемых тетрадях начал общаться с ними в эпистолярном жанре.

Все то, что делает Служкин, по меньшей мере странно с точки зрения педагогических канонов. Однако его личные человеческие характеристики вполне согласуются с целями и задачами, определяемыми для деятельности им же самим. Хотя у Служкина не было хоть какого-то шанса самостоятельно предпослать цели своему курсу географии и тем более всему школьному образованию, в которое он оказался втянут как в уже происходящий процесс, получается, что в несвободном контексте то, что он мог выбрать, - это быть самим собой, - и он выбирает это очень активно.

Итак, уточним, каковы версии миссии учителя. "Kaк педагогический автомат» это одна версия. В ее рамках, если у учителей-людей и есть какие-то свои интересы, специфичные жизненные линии и пр., все это они оставляют за рамками себя как учителей-деятелей в качестве недопустимого содержимого - подобно тому, как пасса- 
жиры в аэропорту перед контролем должны оставить при прохождении контроля свои бутылки с водой. Ситуация характеризуется лозунгом «Ничего личного!» и усмиренной, задушенной, иссушенной субъектностью. Идея миссии полностью вытесняется (замещается) понятием долга - вмененной ответственности. Если понятие миссии здесь и используется (как долга перед государством и т. А.), то только как отчуждаемое. И когда учитель представляет ученикам собой «модель человека», то ученики в данном случае учатся способу следовать именно этой модели: как человек может отчуждаться от себя, человека. Это не очень легко. И у учителей уходит много энергии на то, чтобы ввести природную стихию в ту схему, которой они сами долго учились. (Заметим: Служкин не обременяет себя борьбой со стихией - он предпочитает действовать внутри стихии.)

«Как душный родитель» - другая версия. В ней миссию трактуют так же абсолютистски, как в миссионерской деятельности. «Миссия» для учителя здесь - это личная ответственность - но как долг. То есть вмененная ответственность присутствует как неотчуждаемая. Так своя субъектность при миссионерском подходе понимается как объективность, и основная проблема здесь - впадение учителей во властные отношения с учениками. Ведь если «моя правда» учителя - это истина (абсолютна), то как всеобщую он настойчиво навязывает ее другим, считает обязательной для других и так задает властные рамки. В романе А. Иванова завуч Угроза Борисовна - живой и типичный пример учителя-миссионера, «душного родителя».

«Как увлеченный артист» можно назвать третий вариант, собственно «личную миссию». Это и есть случай Виктора Служкина. Увлеченный артист делает то, что лично ему самому кажется важным. И если разбираться, что же это важное, - это те высветившиеся для сознания рельефы, которые сформировались совпадениями в проекции всей совокупности природных предрасположенностей, опыта и т. А., наложенной на развертывающиеся линии биографической канвы, включенной во всю ситуацию мира. Такой учитель в отношениях с Аругими (с учениками) своим важным делится, даже если Аругие этого не принимают. Например, для Служкина самое важное - «человечность», и он признается другу в неудачах с учениками:

«Я человека ищу, всю жизнь ищу - человека в другом человеке, в себе, в человечестве, вообще человека!... Я из-за них даже сам человеком стать не могу - вот сижу тут пьяный... Ну что делать-то? Аоброта их не пробивает, ум не пробивает, шутки не пробивают, даже наказание - и то не пробивает!» (там же).

В чем разница с миссионерским «душным» подходом? В том, что здесь миссию не объективируют и не абсолютизируют: она частная, личная, - учитель сознает свою субъектность как субъективность. Служкин определяет это так: «Я знаю, что научить ничему нельзя. Можно стать примером, и тогда те, кому надо, научатся сами, подражая. Однако подражать лично мне не советую» (там же).

Такой «учитель-артист» уходит от властной борьбы тем, что лишь предлагает то, что хочет нести в мир, это только дар, причем подлинно бескорыстный - не троянский конь. А предлагать как дар возможно лишь то, что мы сами любим. «Географ» Служкин, не концептуализировавший своей миссии заранее, вдруг обретает ее в интуиции:

«И может, именно любви я и хотел научить отцов - хотя я ничему не хотел учить. Аюбви к земле, потому что легко любить курорт, а дикое половодье, майские снегопады и речные буреломы любить трудно. Аюбви к людям, потому что легко любить литературу, а тех, кого ты встречаешь на обоих берегах реки, любить трудно» (там же). 
Что еще необходимо учитывать: в дичной миссии человек исходит из незаимствованной, личной правды, а поскольку ее цена для самого человека абсолютна, - платит за нее своей жизнью. В смысле этой независимости от мнений, препятствий и даже цены дичная ответственность в дичной миссии должна быть понята как свобода.

Однако в том случае, когда учитель - «увлеченный артист» реализует свою миссию, исходя из свободы, и сталкивается с тем, что его дело не находит признания, значит ли этот конфликт спор об общем жизненном мире? А если так, то разве не будет не-признание означать поражение относительно достижения социальности (способности к общности с Аругими)? Если согласиться с этим, тогда понимание социальности как конформности - соглашательства с большинством, следования утвержденному (властями, авторитетами и т. А.) - окажется обоснованным. И если так, учитель «увлеченный артист» вынужден будет сделать вывод, что данной его миссии нет места в мире?

Но в подобной логике есть принципиальная ошибка подхода. Такой вывод об отсутствии места в мире, уже организованном, утвержденном (властями, авторитетами, большинством), может сложиться, если человек принимает себя за вещь вещного мира, имеющую место в пространстве. Но человеку не может не хватить места в мире, потому что человек приносит в мир свое место с собой. Свое место сам человек создает - так же, как только сам человек создает и воплощает дичные смыслы.

И если вернуться к учительской роли «модели человека», тогда для учеников значение модели учителя как «увлеченного артиста», реализующего свою миссию, - это тоже личные смыслы.

\section{ВНЕШНИЕ УСАОВИЯ - ОТНОШЕНИЕ В ОБЩЕСТВЕ К УЧИТЕАЯМ. «ОБСАУГА», «САУ- ЖАЩИЕ», «САУЖИТЕАИ»?}

Педагоги - участники учительских семинаров и конференций в рамках проекта «Философия учителя» (2013-2016 гг.) ставили вопрос: «Каковы могут быть средства поддержки и развития автономной позиции учителя?» ( «Педагогическое сообщество», 2014: Электронный ресурс). И скорее мы можем назвать данные условия моральными - в том смысле, что подразумеваем «моральную поддержку» деятелей образования со стороны общества. И в том смысле, что само отношение выражает нравственно-ценностные моменты: понимание обществом важности, трудности и ответственности процессов образования и, соответственно, педагогического труда. Отношение к учителям отражает наличие ценности образования в обществе.

Каково же реальное положение дел? Современные учителя чувствуют падение уровня уважения к педагогам в обществе. Российские учителя особенно связывают его с новым пониманием образования как «услуги».

По мнению учителей, эта концепция перевела их в разряд обслуживающего персонала. Протестуя против того, что в обществе школа - сфера обслуживания, учителя вспоминают А. С. Грибоедова: «Служить бы рад, прислуживаться тошно!» Тем самым они предлагают глубокую постановку вопроса относительно разницы смыслов. Это три смысла: «прислуживание», когда учитель оказывается прислугой; «служба», когда учитель - служащий»; «служение», которое ассоциируется с духовной деятельностью человека.

B чем принципиальная разница? В мотивациях - как причине и отношениях - как результате. В первом из трех рассматриваемых случаев мы имеем с одной стороны «клиентов», т. е. потребителей (учеников и их семьи) и присущую им мотивацию про- 
извола и потребления. Со стороны же обслуги, сервиса (т. е. учителей) той мотивации будет соответствовать мотивация угождения, кредо: «Клиент всегда прав!»

А каково должно быть отношение общества, чтобы оно составляло условие автономии учителя? Учителя писали об этом: «Возможность находиться не в оправдательном состоянии» и «право на доверие со стороны “внешних сил" (администрации, родителей и т. А.) в тех вопросах, которые в компетенции учителя (М. М. Челпанова)» (Педагогическое сообщество, 2014: Электронный ресурс).

«Многие... говорят, чем учитель должен быть или не должен быть, как учителя должны работать, как профессия должна развиваться. Все это часто приводит к чувству вмешательства, напряжения, дискомфорта» (там же).

Эти слова и проистекающее из них требование условий для «мирного исполнения работы» вошли в Манифест учительства для XXI в., принятый в апреле 2014 в Страсбурге, в Совете Европы на конференции «Профессиональный образ и этос учителя» (The professional image ..., 2014: Электронный ресурс). И можно заметить, что все приведенные выше определения означают одно: если общество хочет, чтобы учитель мирно и успешно работал, оно должно предоставить ему свободные условия для действий - подобно тому, как родственники пациента, администрация больницы и чиновники Минздрава не стоят под рукой у хирурга с рекомендациями и требованиями, что, когда и как ему делать в своей операции.

Российские педагоги, участники семинара, поднимали вопрос: «Где может и должен размещаться “центр” поддержки автономии учителя: в классе, в школе, в сообществе, где-то еще?» (там же).

Это важный вопрос: наверное, начиная с педагогических коллективов, школьной администрации, родительских комитетов и попечительских советов школы и включая управленцев образования более высоких уровней, все должны были бы поддерживать автономию учителя постольку, поскольку она является необходимым условием его труда.

\section{СОЦИУМ УЧИТЕАЕЙ}

С другой стороны, на внешнем уровне включения в социум социальность учителей выявляется в их социальных позициях, принимаемой ими роли - чаще «авторитетной фигуры»: представителя взрослого мира, представителя власти в школьном социуме, и прежде всего представителя власти научного знания, - роли, консервативной по определению и лишенной свободы, как бывает лишен личной свободы всякий представитель.

В этом смысле объяснимы страх ошибки, доведенный до инстинкта в учительском подсознании, и могучая внутренняя цензура учителей, заставляющая их прислушиваться скорее не к собственному внутреннему голосу, но к внутреннему голосу представляемой ими власти. Как комментируют социологи, исследующие профессиональную культуру учителей, учителя составляют ту социальную группу оплачиваемых работников, которая взаимодействует со знанием, но при этом и не владеет им, и не влияет на создание знаниевого символического продукта (Caria, 2007: 123).

О роли деятелей образования в работе инструментального разума и в циркуляции им произведенного товара мысли М. Хоркхаймер и Т. Адорно заметили, что в области цензуры, начинающейся с «автоматической прозорливости» автора и охватывающей целый штаб редакторов, издателей, переработчиков, именно воспитательная система берется за тотальное обеспечение чистоты, корректности передаваемых текс- 
тов, строго ограничивая их лишь констатацией фактов и расчетом вероятностей, делая тем самым отправление цензурой своих функций уже окончательно излишним (Хоркхаймер, Адорно, 1997: 10).

По-видимому, в том плане, в котором учителя являются «представителями», расширяя в самосознании свою «мы-группу» (по А. Шютцу), наделенную неизбежно нераспознаваемыми социокультурными предвзятостями до неопределенных, сравнительно с другими группами, «всеобщих» пределов общества, они и срабатывают как живые носители «скрытого учебного плана».

С другой стороны, еще действуют «казарменные» условия мира школы, в которых существуют учителя и которые представляют такой контекст общения (социальности базового уровня, по Г. Зиммелю, см.: Зиммель, 1996: 485). Коллектив школы составляет функционально определенную иерархическую структуру и функциональную систему, выстроенные на взаимных профессиональных ожиданиях и обязанностях каждого. Весь этот контекст чувствуется самими учителями как тесная, слишком плотная, жесткая и гомогенизированная среда. Так, автор, работая с педагогами одной из очень успешных петербургских школ в рамках проекта «Практикум учительской философии образования», опросила их о том, что в феномене рабочего педагогического коллектива вызывает у них опасение или протест. В ответ были получены такие характеристики: «эффект толпы»; мнения, «которые сложно переломить»; «размывание индивидуального подхода»; «недооценка в коллективе личностных особенностей и достижений»; «трудность влиться в коллектив из-за плотных сложившихся связей».

Затем, помимо всего прочего, социум учителей - это очень замкнутый мир профессиональной «касты», мало контактирующий с внешним миром, для которого они готовят своих питомцев. Этот контакт сводится в основном к эпизодическому общению с родителями. В собственном замкнутом социуме учителя действуют по строго заданным правилам, знать правила - это их профессиональная квалификация. Они знают правила для себя - научаются соответствовать регламентации и диктуют правила для других, прежде всего правила для учеников, а соприкасаясь с родителями, побуждают или принуждают последних действовать также по правилам. Так, даже в эпизодических контактах с большим миром учителя не выбираются со своей территории, но «втягивают» гостей к себе.

\section{ВНЕШНИЕ УСАОВИЯ: УПРАВАЕНИЕ В ОБРАЗОВАНИИ}

По мнению этносоциологов, внутри институциональных и управленческих моделей образования сама педагогическая среда составляет так называемую власть периферии, или пассивного большинства, способного ради избегания рисков оказывать пассивное сопротивление активной административной «власти центра». И по тем же причинам большее понимание со стороны этой среды получает учитель-инноватор, который официально не будет объявлять свою деятельность инновационной (Саria, 2007: 127-128).

И, наконец, последняя, невероятно острая для российского учительства в послеАние годы проблема: социальность учителей в современной школе испытывает все большее влияние нарастающей бюрократизации, которая означает для них не только дополнительную бумажную (компьютерную) работу, но, что важно, сужает границы их самоопределения, ослабляет значение непосредственного человеческого общения в профессиональной сфере и, главное, постепенно перестраивает их понимание и отношения в направлении формализации - и так влияет на характер социальности. 
Вместе с тем обсуждавшаяся среда общения и педагогический коллектив еще далеко не полностью воплощают в себе ту коллективную субъектность и ту солидарность, которые могут быть названы «педагогическим сообществом» в полном смысле этого слова.

Полагаем, необходимо различить «принятую коллективную» (конформистскую) и «рефлективную» социальные идентичности. Вторая происходит из мотивационного, концептуального и коммуникативного самоопределения, и для последнего в качестве его условий требуется пространство свободы, автономия учителя (Кожевникова, 2015).

На внешнем уровне эти условия очень сильно зависят от типа администрирования, управления в образовании. Выделим схематично, в общем, два типа управления прежде всего для того чтобы поднять проблему управления как необходимого условия. Один тип - это «древняя» прямолинейная модель управления, которая не требует многих комментариев. Аругой тип - более соответствующие современности новые модели управления. Каковы же они? Это прежде всего разные версии синергетического типа управления в образовании (Buckmiller et al., 2014), исходящего из представлений о человеке и его мире как сложной динамичной самоорганизующейся системе (Князева, 2011).

Отличие новых моделей состоит в том, что в них учитывается «принцип круговой причинности» (Г. Хакен), поэтому отдельные части системы (в нашем случае - деятели образования и их первичные коллективы), в свою очередь, должны формировать параметры порядка. В этом случае складывается управление нового типа организационной культуры, представляющей элемент культуры гражданского общества (Сидикеева, 2012: 35-37).

\section{ЗАКАЮЧЕНИЕ}

Обнаруживается, что внутренние профессиональные основания социальности педагогов, коренящиеся в самосознании учителей, связаны с их переживанием и пониманием личной учительской миссии, которая в педагогической деятельности и отношениях может представать в разных версиях: как педагогический автомат, душныий родитель, увлеченный артист и ар.

Внешние же условия воплощены в принципах организации педагогического коллектива и всего социума школы, влияющих на возможность становления подлинного педагогического сообщества. Как результат, социальная идентичность учителей в педагогическом коллективе может формироваться в двух направлениях: «принятой коллективной» (конформистской) или «рефлективной социальной» идентичности.

Продвигаемые бюрократизацией идеологические основания, со своей стороны, ведут к росту отчуждения учителей от их собственных ценностных оснований, которые должны были бы служить основой содержательной общности учительского сообщества. В этом случае ориентация на бюрократические идеологические, а не на собственные ценностные основания педагогов закладывает фундамент конформистской позиции. Аля реализации идеала педагогического профессионального сообщества требуется управление нового типа, воплощающего синергетическую модель в организационной культуре.

Белкин, А. С., Сутырина А. Т. (2009) Ментально-миссионное направление в образовании. M. : Спутник+. 236 с. 
Гусейнов, А. А. (2001) Свобода воли и ответственность. Спецкурс // История философии : учеб. пособие / под ред. Н. В. Мотрошиловой. М. : Феноменология-Герменевтика. 362 с. С. 194-284.

Зиммель, Г. (1996) Избранное : в 2 т. : пер. с нем. М. : Юрист. Т. 2. Созерцание жизни. 608 с.

Иванов, А. В. [Электронный ресурс] // Lib.ru. URL: http://lib.ru/RUFANT/IWANOW_A/ geograf_globus_propil.txt_with-big-pictures.html (дата обращения: 20.11.2016).

Князева, Е. Н. (2011) Система и среда: сопряжение сложности, эмерджентности и управленческой активности // Междисциплинарные проблемы средового подхода к инновационному развитию : сб. статей / под ред. В. Е. Аепского. М. : Когито-Центр. 240 с. С. 74-84.

Кожевникова, М. Н. (2016) Социальность подлинная и ложная как проблема философии образования // Социология образования. №5. С. 44-54.

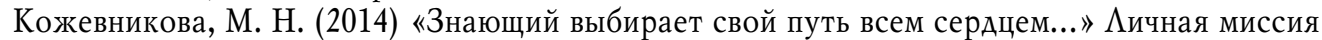
учителя // Учитель наедине с собой : сб. науч. статей / ред.-сост. М. Н. Кожевникова. СПб. : Аема, ФГНУ ИПООВ РАО. 176 с. С. 41-58.

Кожевникова, М. Н. (2015) Субъектность ученика и автономия учителя: образовательнофилософский анализ // Человек и образование. № 1 (42). С. 63-67.

Курлов, В. Ф. (2004) Интеракция институциональной миссии и социального запроса в системе школьного образования : дис. ... А-ра социол. наук. СПб. 331 с.

Малашкина, Е. С. (2007) Педагогическая деятельность как доброделание // Вестник Православного Свято-Тихоновского гуманитарного университета. Серия 4: Педагогика. Психология. № 6. С. 140-143.

Малашкина, Е. С. (2006) Феномен отношения учителя к профессиональной деятельности : дис. ... канд. психол. наук. М. 123 с.

Малякова, Н. С. (2014) Миссия учителя отечественной школы: традиции и современность // Учитель наедине с собой : сб. науч. статей / ред.-сост. М. Н. Кожевникова. СПб. : Аема, ФГНУ ИПООВ РАО. 176 с. С. 17-31.

Педагогическое сообщество (2014) [Электронный ресурс]// Образование человека. Ассоциация развития образования. 30 мая. URL: http://www.o-ch.ru/teacher/seminar/may2014/ (дата обращения 20.11.2016).

Сидикеева, Ю. (2012) К вопросу об управлении в динамично изменяющихся условиях информационного общества // Информационные ресурсы России. № 3. С. 35-37.

Уткин, А. В. (2013) Миссия учителя как предмет теоретического осмысления в истории отечественного образования XVIII - начала XX века : дис. ... А-ра пед. наук. М. 499 с.

Хоркхаймер, М., Адорно, Т. В. (1997) Аиалектика Просвещения : пер. с нем. М. ; СПб. : Медиум. Ювента. 312 с.

Buckmiller, T., Battistone, B., Brown, T., Courtney, M., Stewart, A. (2014) Synergistic Management and Learning Leadership: School Management Towards Instructional Leadership. CreateSpace Independent Pub. 134 p.

Caria, T. (2007) The Professional Culture of the primary school teacher in Portugal: A line of research undergoing development // Sisifo: Educational sciences journal. №3. P. 121-134.

The professional image and ethos of teachers. 24-25 April 2014 - Council of Europe - Strasbourg, France (2014) [Электронный ресурс] // Council of Europe. URL: http://www.coe.int/en/ web/pestalozzi/professional-development (дата обращения 20.11.2016).

Аата поступления: 21.11.2016 г.

\section{TEACHERS' SOCIALITY: EXTERNAL AND INTERNAL CONDITIONS}

\section{N. KOZHEVNIKOVA \\ INSTITUTE OF EDUCATION MANAGEMENT, \\ RUSSIAN ACADEMY OF EDUCATION}

The article researches the problem of teachers' sociality and external and internal conditions for its formation. Sociality is understood by the author as a capability to be in commonality with Others 
(students, colleagues, educational institutions), whereas teachers' sociality is understood as having features in terms of community boundaries, the mode of relations with Others and the type of inclusion in the society.

It is important to understand the issue of teachers' sociality to be able to trace the origins of conformity in society and conformity in education. What is the origin of teachers' professional conformity? The author singles out the elements of the teachers' sociality, depending on which internal and external factors are defined.

The internal factors are manifested in professional self-awareness and are represented in a complex of conceptions, attitudes, experiences of personal meanings and personal responsibility in a teacher's self-awareness. These factors constitute the issues of a teacher's personal mission, they determine the very interpretation of professional community by the teachers.

The external factors refer to the level of engagement of teachers in the professional community; these factors are reflected in organizational principles regarding the teachers' community. Those are determined by institutional and managerial models. These factors are revealed in the formation of the social status, positions, institutional roles of teachers, etc. Regarding their positions and roles, the most common situation in teachers' social life is the confrontation between active administrative 'power of the center' and 'power of the periphery', that is, of the passive majority.

The current social situation in Russia and in the West is determined by the growing influence of neoliberal ideology. Its influence on education leads to an increasing alienation of teachers from their own value orientation. In these terms teachers' social identity within the teaching staff can be formed in two ways: either as an 'accepted collective' (conformist) identity, or as a 'reflective social' identity. However, true solidarity of the teachers' community appears only in the second case. Among external factors the most significant condition for it is the synergetic type of management in education, which is specified by the author.

Keywords: sociality; personal teacher mission; professional teachers' self-awareness; imputed responsibility; conformity; hidden curriculum; social identity; synergetic model of management

\section{REFERENCES}

Belkin, A. S. and Sutyrina A. T. (2009) Mental'no-missionnoe napravlenie $v$ obrazovanii. Moscow, Sputnik+. 236 p. (In Russ.).

Guseinov, A. A. (2001) Svoboda voli i otvetstvennost'. Spetskurs. In: Istoriia filosofii : ucheb. posobie, ed. N. V. Motroshilovoi. Moscow, Fenomenologiia-Germenevtika. 362 p. Pp. 194-284. (In Russ.).

Zimmel', G. (1996) Izbrannoe : in 2 vol., transl. by Germ. Moscow, Iurist. Vol. 2. Sozertsanie zhizni. 608 p. (In Russ.).

Ivanov, A. V. Lib.ru [online] Available at: http://lib.ru/RUFANT/IWANOW_A/geograf_globus_propil.txt_with-big-pictures.html (access date: 20.11.2016). (In Russ.).

Kniazeva, E. N. (2011) Sistema i sreda: sopriazhenie slozhnosti, emerdzhentnosti i upravlencheskoi aktivnosti. In: Sbornik statei: Mezbdistsiplinarnye problemy sredovogo podkboda $k$ innovatsionnomu razvitiiu, ed. V. E. Lepskogo. Moscow, Kogito-Tsentr. 240 p. Pp. 74-84. (In Russ.).

Kozhevnikova, M. N. (2016) Sotsial'nost' podlinnaia i lozhnaia kak problema filosofii obrazovaniia. Sotsiologiia obrazovaniia, no. 5, pp. 44-54. (In Russ.).

Kozhevnikova, M. N. (2014) «Znaiushchii vybiraet svoi put' vsem serdtsem...» Lichnaia missiia uchitelia. In: Uchitel' naedine s soboi : sb. nauch. statei, ed. M. N. Kozhevnikova. St. Petersburg, Lema, FGNU IPOOV RAO. 176 p. Pp. 41-58. (In Russ.).

Kozhevnikova, M. N. (2015) Sub'ektnost' uchenika i avtonomiia uchitelia: obrazovatel'no-filosofskii analiz. Chelovek i obrazovanie, no. 1 (42), pp. 63-67. (In Russ.).

Kurlov, V. F. (2004) Interaktsiia institutsional'noi missii $i$ sotsial'nogo zaprosa $v$ sisteme shkol' nogo obrazovaniia: Dis. ... Doctor of History. St. Petersburg. 331 p. (In Russ.).

Malashkina, E. S. (2007) Pedagogicheskaia deiatel'nost' kak dobrodelanie. Vestnik Pravoslavnogo Sviato-Tikbonovskogo gumanitarnogo universiteta, issue 4: Pedagogika. Psikhologiia, no. 6, pp. 140-143. (In Russ.). 
Malashkina, E. S. (2006) Fenomen otnosheniia uchitelia k professional' noi deiatel' nosti : Dis. ... Candidate of Psychology. Moscow. 123 p. (In Russ.).

Maliakova, N. S. (2014) Missiia uchitelia otechestvennoi shkoly: traditsii i sovremennost'. Uchitel' naedine s soboi : sb. nauch. statei, ed. M. N. Kozhevnikova. St. Petersburg, Lema, FGNU IPOOV RAO. 176 p. Pp. 17-31. (In Russ.).

«Pedagogicheskoe soobshchestvo» (2014) Obrazovanie cheloveka. Assotsiatsiia razvitiia obrazovaniia. 30 May [online] Available at: http://www.o-ch.ru/teacher/seminar/may2014/ (access date: 20.11.2016). (In Russ.).

Sidikeeva, Iu. (2012) K voprosu ob upravlenii v dinamichno izmeniaiushchikhsia usloviiakh informatsionnogo obshchestva. Informatsionnye resursy Rossii, no. 3, pp. 35-37. (In Russ.).

Utkin, A. V. (2013) Missiia uchitelia kak predmet teoreticheskogo osmysleniia $v$ istorii otechestvennogo obrazovaniia XVIII - nachala XX veka : Dis. ... Doctor of Pedagogy. Moscow. 499 p. (In Russ.).

Khorkkhaimer, M. and Adorno, T. V. (1997) Dialektika Prosveshcheniia, transl. by Germ. Moscow, St. Petersburg, Medium Iuventa. 312 p. (In Russ.).

Buckmiller, T., Battistone, B., Brown, T., Courtney, M. and Stewart, A. (2014) Synergistic Management and Learning Leadership: School Management Towards Instructional Leadership. Create Space Independent Pub. 134 p.

Caria, T. (2007) The Professional Culture of the primary school teacher in Portugal: A line of research undergoing development. Sisifo: Educational sciences journal, no. 3, pp. 121-134.

The professional image and ethos of teachers. 24-25 April 2014 - Council of Europe Strasbourg, France (2014) Council of Europe [online] Available at: http://www.coe.int/en/web/ pestalozzi/professional-development (access date: 20.11.2016).

Submission date: 21.11.2016.

Кожевникова Маргарита Николаевна - кандидат философских наук, ведущий научный сотрудник Института управления образованием Российской академии образования в СанктПетербурге. Адрес: 191119, Россия, г. Санкт-Петербург, ул. Черняховского, д. 2. Тел.: +7 (812) 764-11-94. Эл. aаpec: margaritakozh@yandex.ru

Kozhevnikova Margarita Nikolaevna, Candidate of Philosophy, Leading Researcher, Institute of Education Management, Russian Academy of Education. Postal address: 2, Chernyakhovskogo St., St. Petersburg, Russian Federation 191119. Tel.: +7 (812) 764-11-94. E-mail: margaritakozh@yandex.ru 